TJP, 5, 2 (2013), 1-20

ISSN 0975-332X | https://doi.org/ 10.12726/tjp.10.1

\title{
Images, Reality and Truth: Some Philosophical Considerations
}

\author{
Santiago Sia*
}

\begin{abstract}
Developments in technology and communications have enhanced the status and role of imaging. They have resulted not just in the excellent quality of images but also in the speed and ease of distributing or communicating them. But with the welcome advances have also come undesirable and even threatening consequences for both individuals and society. These have presented challenges and issues which need to be addressed urgently. Focusing first on the tension between image and reality, it provides a philosophical background to the debate. It then discusses the question of truth and the related issues of the right to know, freedom of speech and privacy. It provides the foundation for these fundamental rights but also examines the tensions or conflicts in their exercise. It also discusses some guidelines to deal with these challenges and issues; namely, the criteria of appropriateness and acceptability and the importance of accountability. It suggests that in addition, given the frailty of human nature and the lessons of history, society also needs the support of laws and policies.
\end{abstract}

Keywords: Imaging, Truth, Right to know, Freedom of speech, Privacy

\footnotetext{
* Professor Emeritus of Philosophy, Milltown Institute, Dublin, National University of Ireland, Ireland; ssia@milltown-institute.ie
} 


\section{Imaging in the Contemporary World}

The tremendous advances made in imaging in our contemporary world have been a great boost to many of us. We have certainly benefited from the various developments in this area, whether in technology ${ }^{1}$, medicine ${ }^{2}$, communications ${ }^{3}$, in the film industry ${ }^{4}$ or just in ordinary life. ${ }^{5}$ We can be truly grateful for the improved clarity and greater accuracy of images - for example, digital and 3D imaging - as well as for the impressive ease and fantastic speed of relaying those images to every corner of the world. Just think of Facebook, Skype, YouTube, among others. It can be claimed, with some justification that individuals, society and the world itself have progressed because of these advances. It would certainly be no exaggeration to acknowledge that the world we live in has been transformed radically by the widespread proliferation and productive use of images. It cannot, of course, be denied either that not everything is positive about these advances and their usage. One has merely to consider the abuses and the crimes committed which are associated with imaging-again in the very same areas of life where the advances have contributed to their betterment. Certain developments in the recent past have certainly confirmed that. ${ }^{6}$

1 The tremendous development in and the widespread use of information technology generally and of the internet particularly would have been unbelievable a few years ago.

2 Cf. Heiner Fangerau et al. (eds.), Medical Imaging and Philosophy: Challenges, Reflections and Actions (Stuttgart: Franz Steiner Verlag, 2012).

${ }^{3}$ This is well exemplified by the role that Facebook played in effecting change during the Spring revolution in the Arab world.

${ }^{4}$ An example of this - from a personal point of view -is the breathtaking photography in the film Samsara. It was done in such a way that it elicited a range of emotions merely-in the absence of any dialogue-from watching it and listening to the accompanying music.

${ }^{5}$ The protection offered by CCTV in residential homes and commercial shops has been welcome. It has been a great boost in tracking suspects and criminals. It certainly a facilitated a speedy outcome in the recent murder case of an Irish woman in Australia.

${ }^{6}$ At the time of the writing of this essay, the media had been giving full coverage to the widespread disturbances prompted by the film-and 
In this essay, my focus will be less on decrying the negativity that is legitimately equated with imagery but rather on providing a philosophical context and some considerations in the hope that these will facilitate a better understanding and appreciation of the situation we find ourselves in today due to these advances. At the same time, my hope is that these considerations will help facilitate a greater awareness of fundamental issues that need to be addressed constantly as well as promote protective and corrective vigilance over abuses.

\section{Image versus Reality}

Any reference to image and reality, particularly in a philosophical context, will inevitably bring us to Plato, the great Greek philosopher of ancient times. In his rather picturesque way of discussing truth, he made use of the distinction between images (concrete representations on the wall of the cave) as opposed to true reality (outside the cave). Warning that images provide us with an inadequate and even falsified representation of reality since they are merely shadows or copies - he insisted that truth can only be found in confrontation with reality itself. While images may serve some purpose, they cannot be relied upon for an accurate knowledge of reality. For this reason, he tirelessly argued, we need to probe deeper, widen our view and persist in our quest if we are to enrich our development as seekers of truth.

Plato's discussion of image and reality and his standpoint on the matter have certainly triggered the long-running dispute between those who champion sense experience (called empiricists) or perception insofar as, in their view, it provides us with an immediate and measurable grasp of reality versus those who uphold reason rather than the senses as the source of truth (called idealists). Since our senses can easily mislead us, we should, according to the idealists, strive to form ideas, abstracted from the particularity and changeability of any grasp of reality by our

more recently, a cartoon published in a French paper - which purportedly insults the prophet Mohammed and constant updates on the situation following the publication and dissemination of specified photos of members of the British royal family. 
senses. The idealists thus emphasise that truth can only be attained by reason.

Our acceptance of human nature as rational would seem to favour the idealist standpoint. Indeed, we distance ourselves from the animal world insofar as we are endowed with the ability to think and not just to sense. On the other hand, the empiricist camp has strong supporters, particularly in the empirical sciences and in ordinary life. For many of us, professionally and personally, credible and reliable evidence comes from experienced reality rather than from thought reality. In this context, images arising from sensory experience have a powerful role to play. They do not just capture our immediate attention but they also have a way of resonating with our own experiences.

The dispute between the empiricists and the idealists inevitably makes one wonder whether there is a third point of view, particularly since there seem to be merits in both of them. After all, as human beings, we do possess reason (and free will) and senses. Both provide us with some grasp of reality; hence, both of these must be a source of truth and a channel to reality. Indeed there is a philosophical school, called realism - there are variations of it, of course-which connects the senses (source of images) with reason (responsible for ideas). Its standpoint can be summed up in this adage from Scholastic philosophy: Nihil in intellectu nisi prius in sensu (nothing is in the intellect without having been previously in the senses). ${ }^{7}$ There is a certain continuity, therefore, in knowledge since any ideas we have originate from our senses. Sensory experience is in this way regarded as an initial stage, with thinking a later stage, in the entire process of knowing reality. The problem, of course, is how to account for that continuity in the process of knowledge since images and ideas, as products of each stage of the process, as it were, are very different in nature and status.

7 This school of thought has to be distinguished from another school which holds that humans have innate ideas, which is sometimes associated with Plato who maintains that the knowing process entails "remembering" what we already know. 


\section{The Philosophical Context as Backdrop}

The philosophical context sketched above does provide an interesting backdrop to our consideration of image and reality. It highlights the importance of the topic and provides some kind of focus. But how appropriate and relevant is it to our present scenario? Interestingly, many of our contemporary discussions can actually be traced back to a number of these philosophical disputes. In fact, at times it would be difficult to understand and appreciate these without some reference to the seemingly abstract philosophical discourses that would seem to interest only a few. More significantly, much of contemporary discussion of viewpoints, issues or topics is underpinned by standpoints or assumptions, which need to be made explicit in a philosophical discussion to enable us to evaluate them properly.

This is certainly the case with the situation we face today because of the advances in imaging. The philosophical context within which we get a glimpse of the disputes can help us understand the nature and features of images and how they contrast with reality itself. In fact, many of those dealing with the creation of images, for example in advertising and the media do capitalise on these. The so-called pulling power of images is well-known and well-utilised by these, even more so today because of further developments in technology and computing.

It will be recalled that Plato metaphorically describes images as mere reflections on the cave-wall and hence apparent, rather than true, reality. He also reminds us of the transitoriness and fickleness of these images. While they can be graphic and captivating-a feature that is given significance in advertising and the mediathey can be misleading, a point stressed by their critics. For Plato, true reality can only be found when we go beyond the images and confront what is (emerging from the cave to see the sun) rather than what appears to be. The idealists-depending on which variety of idealism one has in mind - would be very much on Plato's side although would not necessarily endorse Plato's analogy. The empiricists, however, would have us appreciate our sense experience, which yields the images, as genuine and more credible knowledge, inasmuch as it is verifiable, as opposed to abstract 
ideas, the result of much "theorising". The empiricist's point of view and regard for the resulting images would find much support among those who value images themselves in our professional and personal lives.

In the above reference to Plato and to the dispute between empiricism and idealism the contrast between images and reality itself, between apparent and true reality, is given prominence. In contrast, it is in the connectivity between them that the realist's position can be of particular relevance to this philosophical consideration. What is the relationship between images and reality? How do images impact on our knowledge of true reality? What role do our senses and our reason play in the acquisition of knowledge? While these questions are also addressed in the philosophical disputes referred to above, the issue of truth is even more striking when one probes into the realist's position. Where does truth really lie? If the senses provide us with an initial grasp of reality, can one have truth at the stage of images or only at the stage of reason? Or are there different kinds of truth?

\section{Truth as a Consideration}

Given the dazzling developments in the creation of images and their impact on all of us, truth in this case is definitely a concern that needs to be addressed more widely. One begins to wonder, given the widespread use of images and their seemingly faithful reproduction of reality, to what extent they can be regarded as reliable data. We are aware that a picture is more effective than a thousand words, but many times the picture or the image even replaces reality itself in the minds of many. We have become witnesses today to the creation of virtual reality which some are beginning to regard as reality itself. The creativity of film-makers and photographers sometimes makes it easy to confuse real actors or sceneries with those which have been created by talented graphic artists.

The issue of truth and the question of truth have always been of concern to philosophers, irrespective of which side of the dispute one belongs to. Of course, truth is not their exclusive prerogative. Although in ordinary life or in our varied professions we do not 
always focus on it, truth at all times underpins what we do and how we act. Nonetheless, the concern for truth and its implications does occupy much of the philosopher's attention. Moreover, it is a philosophical consideration inasmuch as it is a fundamental issue.

We have already noted the nature of images as described by the philosophers cited above. Despite the empiricists' view that sense experience, which results in images or percepts, is the more reliable guide to truth, Plato's reference to images as merely shadows or copies of reality is a more helpful way of distinguishing between the representation of reality and the reality itself. It facilitates the appreciation of the role of subjective factors in the assimilation of data, and thus alerts us to a more critical understanding of the status of images. The realist position is even clearer here, expressed in the Scholastic adage: Quidquid recipitur recipitur ad modum recipientis (whatever is received is received according to the mode of the recipient). Insofar as images are products of the senses experiencing or being in contact with the reality, these images will take on the characteristics of the senses, particularly the eyes of the beholder. That is how they will be received. Thus, despite the common claim that one can trust the senses as evidence-hence, as bearers of truth-a more credible view is that not only can senses mislead but that they are also subjective. In this regard, images would be characterised as merely reflecting reality and would have a more limited truth-value.

In the present context of the advances in the development and use of images and the issue of truth, how does this philosophical consideration help us? The suggestion being made here is that: (1) alerting us to the nature and status of images should sensitise us not only to the impact of images but even more so to the responsibility that rests on the shoulders of image-makers and (2) one can also point to the need to educate ourselves adequately so that images are received in a more critical way. Let us pursue these two points further.

In the use and creation of images, precisely because they are so powerful, one cannot but admire human creativity. This human gift should indeed be encouraged not just because the end-result can be fascinating and even mind-boggling but also because the development of our humanity in all its positive features is a human 
task and responsibility. But creativity itself is not the main consideration. Rather it is the wholesome development of humanity. Creativity is meant to facilitate that, not thwart it. Unfortunately, creativity can at times be exercised-including by many image-makers - in such a way that instead of leading us to genuine reality and truth it confuses and misleads those who are at the receiving end. Accordingly, there really is a need for imagemakers to be aware of-and to heed-the responsible challenge that confronts them.

The same can be said of the recipients of these images. That is practically all of us, given the fact that our contemporary world is truly an image-world. In every aspect of life, images surround and confound us. Again, we should welcome the progress made in this field. While not everyone would agree that all these developments in imaging have made our world a better one to live in, it has to be admitted nonetheless that they have transformed it radically. But we do need to understand images for what they are-and here the philosophical context can be of help. They do not and should not replace reality. We need to go beyond the images. We need to critically assess them. And we do need to contextualise them. For that to happen, we must educate ourselves.

\section{Another Look at Truth}

But what is truth? How do we know that we are in possession of truth? How can we educate ourselves so that we are led by the truth, rather than by the images? These are age-old questions which nevertheless continue to challenge life in society to this day. The developments in the production and circulation of images that we have noted certainly give these questions a starker profile. For those reason philosophical conceptions of truth, illustrated in the debate noted earlier, need to be re-examined today.

We have noted that a working definition of truth, implicit in the discussion above, is that it corresponds with the facts or with reality. A popular way of expressing it is when one claims that it is "telling it as it is" without any embellishment, any value judgment or any comment on the part of the speaker. The claim is that one is thereby being "objective". But there is a presumption in this 
common view - and it needs to be challenged just as subjectivism or relativism must also be critically assessed. It has to be pointed out that imparting truth or truths is not like delivering goods. There is always a certain amount of subjectivity precisely because one cannot completely exclude a contribution, conscious or unconscious, from the speaker. In the same way that any form of communication, including images, is received in accordance with the nature of the recipient-as was already noted-so any communication from the communicator is always tainted with the background, concerns and perspective of the communicator. All that one can really and legitimately claim is that one makes an effort to be as objective as is possible. Truth, therefore, in the human sphere, is hardly "telling it as it is" ${ }^{8}$

So to what extent can one have or communicate the truth? Can one be objective at all? Are relativism and subjectivism right after all? Drawing on the insights of process philosophy, a contemporary school of thought associated with Alfred North Whitehead and Charles Hartshorne, we can arrive at a perspective that may facilitate our consideration of these questions. Using again the working definition that truth is correspondence with reality, ${ }^{9}$ one can make a crucial distinction between absolute truth and relative truth. In other words, truth ultimately is about the reality itself (absolute truth) rather than experienced or thought reality (relative truth). Since our contact with reality is always in accordance with our nature as knowers ${ }^{10}$ there is always an element of subjectivity. Hartshorne puts it rather succinctly when he asserted that "our knowledge of the absolute is not absolute". That is to say, assuming

${ }^{8}$ Even the telling of facts as facts involves a selection and judgment on the part of the speaker. For example, the citing of a date as 17 March 1970 already indicates that one has chosen to refer to it using the Arabic/Christian preference for listing dates rather than another system. This is why there is much truth in the claim that whatever is said is not just informing us but also telling us something about the speaker.

9 The "correspondence criterion" of truth can be complemented by the "coherence criterion" in this perspective inasmuch as it pays particular attention to the content of knowledge and the role of the knower ${ }^{10}$ This point is reminiscent of, but not equivalent to, Kant's "reality itself vs. reality as it appears to us" distinction. 
that there are absolute truths, our grasp of these same absolute truths is relative.

The claim that there are absolute truths is supported not by tangible evidence, which empiricists would be inclined to insist on, but by a logical process of reasoning. In other words, it is not and cannot be an empirical fact that one can point to. Rather, it is a matter of realising that not everything, literally everything, can be relative simply because the allegation that everything is relative is to make an absolute of the allegation itself. In that case there would be at least one absolute truth; namely, that everything is relative. Rather, relative truths are relative precisely because they are anchored on what one must conclude as absolute. ${ }^{11}$

To sum up, absolutism, which to some extent shares some of the characteristics of extreme idealism, errs in not realising that as knowers, we cannot be completely detached, a point made above. In this respect, empiricists and realists are right in acknowledging the role of sense experience. One could even go further and accept that there is always a subjective factor, in varying degrees, in all knowledge and communication. In other words, truth is also always relative. On the other hand, complete relativism and subjectivism are mistaken in rejecting absolute truth or objectivity. The process perspective on truth thus is at the same time critiquing both extremes. Both positions, according to this perspective, are guilty of completely ignoring the other side.

This philosophical consideration has some implication for the status and role given to imaging. While images may contain truth-or factual evidence, the phrase commonly used by those who advocate their dominant use as if to clinch their claim to truth-they should never be absolutised. The nature and the features of any image indicate that they have a relative value as far as the issue of truth is concerned. This is a point worth bearing in mind by both image-makers - particularly when they are tempted to endow them with such importance-as well as by those exposed

11 It will be noted that there will always be difficulties in listing absolute truths. But this difficulty does not contradict the claim that there are absolutes precisely because there must be absolutes. Otherwise, relative truths cannot be considered relative either. 
to the images - lest they are so captivated by them that they begin to dominate their lives and outlook.12 Of course, they should be given the importance that is rightfully theirs, but they should not be elevated to a suspect level either.

\section{The Right to Know, Freedom of Speech, and Privacy}

This philosophical consideration of truth does need to be pursued further, however. This is because while the above consideration focused on a particular context, namely the development and dominance of images in present-day society and the consequent challenges to us, it opens up a wider field for our attention here insofar as this situation is really part of the larger picture in the media, whether it is graphic, print, verbal or digital. An important function of images-and this accounts for their appeal-is the sharing of information. The use and distribution of images, it seems, is part and parcel of the human need to communicate with one another. One can even talk of this need being heightened and motivated because of the tremendous development in the technology and availability of communication tools and techniques. Again, much of this development is to be welcomed. One will have to admit that it has resulted in considerable improvement for society as a whole even if one must also decry some of the consequences to society.

But the sharing of information inevitably brings up fundamental issues such as, among others, the right to know, freedom of speech and privacy. ${ }^{13}$ The proliferation of sources of information, the everincreasing possibilities of retrieving that information, and the speed of divulging that information world-wide have created a new

12 Sometimes this happens because of the status given to the photos in fashion magazines - and now with images on the internet.

13 They have become particularly relevant in light of the Levenson Inquiry in England over phone-hacking and the call for inquiries into the handling of the Twitter information by Radio Telefis Eireann in Ireland in two of its programmes during the presidential campaign. There is also the ongoing dispute regarding the sharing of data contained in the electronic files of various agencies and even in internet servers for various uses. There have also been the legal issues connected with WikiLeaks. 
situation that threatens one's life in society. Added to this problem is the difficulty, and even impossibility, of removing false information that remains available to all and endangers one's reputation. ${ }^{14}$ Cyber-bullying has ruined many lives, particularly the vulnerable. Somehow the ability and willingness to eradicate the false information are not matched by the skills and expertise of those who upload the information in the first place. It is not surprising therefore that many today have serious reservations about, and even reject outright, such sources of information as the internet, e-mail, Twitter, Facebook and others. The abuses at times can be so overwhelming to the extent that they indicate a worrying trend in certain quarters in society. That worry extends to the retrieval of highly confidential matters that could endanger lives. But those who do engage in what has become known as "hacktivism" justify their action by insisting on the right to know and freedom of speech and accusing those who have the information of covering up. ${ }^{15}$ Clearly, there are critical issues regarding the dissemination of information which deserve serious consideration far beyond just the communication of images.

Those who insist on everyone's right to know, which underpins the sharing of information, are correct to point out that this is indeed a human right and not just a legal right. ${ }^{16}$ In that sense, it is really more fundamental and pervasive than any recognition of it by society. In fact, because it is a human right, one can rightfully challenge a society that limits it or worse, thwarts it. Political systems have suffered their downfall because, among others, they have blocked the communication of information which their citizens have claimed a right to be given. There have been numerous protests and rallies denouncing such political regimes.

14 Those who print or communicate false or misleading information seem to ignore the fact that despite an apology or correction in a later edition or broadcast, one cannot really retrieve the previous information since the readers and the audience do not always remain the same. Thus, vigilance and sensitivity are paramount from the start.

15 Cf. "How Hackers Changed the World," written and directed by Brian Knappenbergen and aired on BBC Four, 20 February 2013.

16 A related phrase that is in currency these days is "transparency" in all one's dealings. 
Many have suffered, or even sacrificed their lives, to protect this right.

This human right to know is rooted in human nature itself. As Thomas Aquinas pointed out in his discussion of the natural law, which he regards as the basis for ethics, the awareness that human nature is directed towards an ultimate goal of fulfilling itself individually and collectively-cannot be accomplished if it is not provided with the opportunity to develop itself. ${ }^{17}$ Since human nature is rational and since a necessary means to its flourishing as rational is knowledge, one can truly and justifiably assert the right to know. That right to know extends to getting information that will contribute towards one's rationality.18

While the human right to know is indeed part and parcel of our human nature, it does not, however, extend to getting every kind of information or even to every truth. This consideration is often ignored to the detriment of everyone. ${ }^{19}$ The right to know is a basic right. It is also a universal right. But it should not be confused with an imagined or claimed entitlement to a particular piece of information, or even a specific truth. It does not cover retrieving every single datum or ferreting out details from every source. While the right to know is an individual right, by which is meant that every human being possesses it, it does not confer a right to solicit information from lawfully protected sources. Nor does it necessarily override the legitimate need to shield the information from those seeking it. This is because the right to know is exercised in an important context; namely, one's involvement with others and with society at large. This right, while fundamental, does not take away one's duty to acknowledge and respect the rights of other individuals and of society itself. The human right to know

17 For Aquinas, the ultimate end of human beings is communio, participation in the very nature of the Creator.

18 It is for this reason that one can rightfully assert everyone's right to education.

${ }^{19}$ A recent example of this is the prank phone call made by two Australian DJs to the hospital enquiring about Kate Middleton. To claim that the tragic death of the nurse who answered the phone was "unforeseen" does not lessen the necessity to consider seriously all possible consequences, especially to those who are victimised, before undertaking such a deed. 
should not, therefore, be regarded as a blanket assertion, which unfortunately is sometimes the case in certain situations or with certain individuals or groups.

Connected with the right to know is the issue of freedom of speech. Again, the basis for asserting freedom of speech is our human nature. Not only are human beings endowed with an intellect but they are also gifted with free will. Unlike non-humans, human beings can choose freely. They can exercise their ability, when faced with various options, to opt for one rather than another. This gift and ability, inherent in what makes one human, includes being able to speak or communicate freely, unhindered by any exterior cause or factor. Anyone who tries to curtail, restrict or deny that right is violating a fundamental human right. A government that does not honour this right is rightly criticised or denounced. It also provides a basis for legitimate protest and opposition. At the same time, however, it must be borne in mind that the right to speech is not, and cannot be regarded as absolute inasmuch as it is a right that impacts on others. To claim freedom of speech because one simply wants to exercise it is being irresponsible. For speech to be effective, it has to be heard. Unlike talking to oneself privately, the exercise of the freedom of speech connotes that there is a hearer or receiver - and that other party will be affected. This is why freedom of speech is really a relational right, i.e. it connects and is not just exercised. Many supporters of this right seem to forget this basic point. Accordingly, one must-in the very exercise of the freedom to speech - be aware of and respect the other party or parties.

This brings us to the equally fundamental right to privacy, another right so often asserted not just in the context of a tension with the right to know or the freedom of speech but also in various situations when someone else interferes with or intrudes into one's "space" - physical, intellectual, emotional and so on. ${ }^{20}$ At times this right is associated with one's strong wishes to "be left alone" by, or

20 A recent controversy in this regard is a piece of Facebook's facialrecognition technology, the so-called "tag suggest" feature, in Europe. Opposed due to privacy laws, Facebook has had to switch it off in the meantime. Previously, there had been unease over the technology developed by Google Earth over the mapping of streets. 
"to create a distance" from, others. The right to privacy extends to groups or societies and is seen as crucial in their development, and any interference by outsiders is considered to be an unwelcome encroachment. This is particularly true in the case of the protection of sensitive material. ${ }^{21}$ So to what extent is it, firstly, a truly fundamental right? Again, its basis is our make-up as human beings. There is something in each of us that is unique to each of us. For this reason, every individual has rightly been called "a world unto itself". That irreplaceable status is never duplicated, and is the basis of self-esteem. Since it is coming from oneself rather than endowed on one, ${ }^{22}$ it cannot be taken away, overridden or violated without defacing one's very humanity. Given the nature of this basis, the right to privacy is indeed fundamental. It thereby imposes an equally fundamental obligation on everyone else to acknowledge and respect it. ${ }^{23}$ Thus, prying information from any of us or exposing one to public scrutiny to the extent that it degrades us, i.e. robbing us of our very humanity, is justifiably challenged or even stopped. In the case of a group's or society's comparable right to privacy, not only is it also based on the nature of the individuals comprising the grouping but it could also be its very survival-or at least its well-being - that is a stake. In varying degrees, a threat to it could be a threat to its very existence, and it is understandable as well as justifiable that the group or society as a whole would seek to protect it.

A related consideration here is the issue of confidentiality. Confidentiality is an acknowledgement of the right to privacy inasmuch as when one confides or entrusts information on another, it is with the expectation that no one else is party to the information. It remains private. One could even go further and

21 Debates about, and tensions over, this particular issue has been heightened and broadened because of developments with WikiLeaks.

22 This claim can still be asserted even if one takes the religious view that it is a gift from the Creator.

23 The trend of selling or circulating personal data that one has entered into the websites of companies when doing business with them and photos in social networking sites is worrying. Fortunately, there are moves to update the data protection laws in Europe (drawn up prior to the internet) to eliminate some of the abuses. 
claim that a breach of confidentiality is tantamount to trampling the confidant's right to privacy. At the same time, however, there can be a tension since one cannot hide behind the curtain of confidentiality or the right to privacy if by upholding it and because one is protecting it, other rights are ignored and even endangered. Thus, such situations lead to questions such as: To what extent should one's right to privacy be respected? If someone entrusts information on the basis of strict confidentiality, are there circumstances which can override the promise to maintain confidentiality, particularly if it is clear that such information would not have been entrusted in the first place? Is confidentiality such that it must be maintained even if the consequences are grave? ${ }^{24}$

It is obvious, from what has been stated here, that the right to privacy and the related right to confidentiality would come into conflict-as has earlier been pointed out-with the right to know and the freedom of speech, both of which have already been shown to be fundamental. Accordingly, certain guidelines or laws need to be drawn up and have been drawn up. This is because the right to privacy is situational, that is to say, it is asserted because one is in society. If one were to be in complete isolation-which is not possible realistically - then there would be no need even to be aware of it. There would be no one to interfere with it. But because we live in the immediate surroundings of others - and affect one another - then it is inevitable that, while fundamental, it is not a right that trumps the right of others to secure information about one or relevant others, or to impose on one an obligation to be more open about oneself or one's actions. In other words, the right to privacy is not a complete withdrawal from the social aspect of one's humanity. It is certainly not an alibi to ignore one's obligations to others and to their safety and welfare.

${ }^{24}$ These questions have certainly come to the fore recently because of abuses in various areas and spheres which have been covered up by those in authority resorting to the alleged need for confidentiality. 


\section{Appropriateness, Acceptability and Accountability as Guidelines}

It will be obvious from this discussion of the right to know, freedom of speech, and privacy, as a corollary to the original discussion of the issue of truth in the context of images, that living in society creates - as is to be expected - a rather complex situation. How do these rights feature in named circumstances? What happens when there is a tension or even a conflict between these rights? How does one reconcile these? Who has the authority to address and redress the conflict?25 The difficulty with these questions - and for anyone attempting possible answers - is that they are dependent on the specificity of each case. It would be unhelpful and in fact foolhardy to attempt answers that could be regarded as generally applicable. Equally, it would be unwelcome and even preposterous to state that there can be no answers because each situation is so unique. Somehow and in some way, answers must be provided if one is to continue living in society which we all must do - and to meet its challenges.

I should like to suggest that the criterion of appropriateness can be of help with our thinking in the present scenario; that is to say, whatever is appropriate in a given instance would be the determining factor. We do need, however, to examine both the criterion and its usage more closely as certain connotations, as is the case with every word, are associated with it. First of all, appropriateness as used here does not mean that what one regards as appropriate is completely subjective, i.e. totally dependent on the speaker or agent. Neither is it totally tied to the particular situation. It is not entirely limited to a specific time either. As was set out previously, our considerations of these issues should indeed take into account circumstances and subjective features but we have likewise noted the need for an objective basis of one's answers. The claim here is that the criterion of appropriateness, contrary to the other connotations, does this. This is because one's

25 See 'Balancing Individual and Public Interests: A Philosophical Analysis,' in my Ethical Contexts and Theoretical Issues: Essays in Ethical Thinking (Newcastle upon Tyne: Cambridge Scholars Publishing, 2010), pp. 87-96. 
judgment of what is appropriate in a given circumstance should be shaped by one's knowledge of both the concrete and abstract dimensions of the situation. It is showing sensitivity regarding the content, activity, or decision. It is alert to the suitability of both the material and its method of implementation. It is a realisation that the agent, the recipient and the communication itself are all involved or to be considered in what one deems appropriate. In short, appropriateness means that ultimately it is a judgment that one has to make in the face of the specificity of the situation against the background of certain fundamental considerations. It is not a mere opinion, view or choice. ${ }^{26}$

This means that a considerable amount of responsibility rests on whoever, be it an individual or a group, judges that it would be appropriate to communicate or display images, exercise the right to know, claim freedom of speech, breach confidentiality, or withdraw information. Since a judgment, and not just an expression of opinion, is called for, it must be well-informed and substantiated. What is at stake, after all, are fundamental rights that all parties possess and must be respected. These are not mere slogans that are mouthed or issued. Judging a course of action or an activity to be appropriate, in keeping with our rational human nature, demands consideration of several relevant factors, including the well-being of all and not just the interests of one side. The inevitable subjective feature of this criterion, which has been acknowledged, simply means that one has to take measures to ensure that one's judgment is not completely one-sided. The criterion of appropriateness actually makes it open to others to question whether what one individual or a group has judged to be appropriate is right. Because the display of images or communication of information affects the recipient, because the

26 In the Denis O'Brien claim of defamation against the Irish Daily Mail, which he won, the jury agreed that the article on him was the author's honest opinion but said that it was not based on fact and was not in the public interest. The defence of honest opinion in a major defamation was introduced in Ireland as part of the Defamation Action 2009. Criticising the outcome, Associated Newspapers lamented the alleged demise of being able to voice strong opinions in a democracy. Cf. Irish Times (February 15, 2013), p. 5. 
claim to freedom of speech can run counter to another's right to privacy, because breaking confidentiality can jeopardise security, it is not enough for someone or some group to simply claim that, as far as one is concerned, the activity or course of action is appropriate. ${ }^{27}$

This observation brings us to the second guiding principle being proposed here: acceptability. Admittedly, its introduction here risks suspicion since after all, what is acceptable even for the majority is not necessarily what is right. Acceptability as a criterion is too close to convention, a standard rightly criticised by Plato. He pointed out that many of the practices during his time may have been acceptable to the society but he questioned whether they were just. Moreover, what is acceptable may be suitable to certain parties and yet may in itself be unfair or even harmful. It may even be a violation of certain rights. Nonetheless, the criterion of acceptability provides an important consideration in ascertaining the merits of one's judgement of appropriateness; namely, it makes one ask whether the activity or course of action is truly acceptable to those who will be affected by it. ${ }^{28}$ Asking that question provides some kind of corrective to the judgement of appropriateness inasmuch as it enables one to be more objective.29 Taking into account the criterion of acceptability amounts to considering the susceptibility of the recipient of one's communication, activity or decision. Moreover, acceptability as a criterion also applies to the content, i.e. the image or the information. One must also scrutinise it as to whether it will generally be accepted as well as to whether it will be acceptable to the specific recipient or recipients and how it will be received. ${ }^{30}$

27 One wonders how those who distribute or upload pornography - when children are both the subject and possible recipients - can consider their action as appropriate. The same can be said about those who incite violence through these channels of communication.

28 Paparazzi, among others, really need to consider this point seriously.

29 This is not the same, however, as merely eliciting consent since a consensual decision does not always make the activity right

${ }^{30}$ One of the rather unwelcome developments of the facilities of Facebook or YouTube is the rush to upload practically anything, or going viral irrespective of the content of the image or information. There is need to 
The third criterion that is being suggested here is: accountability. We have been discussing various rights principally in connection with imaging and have noted that the basis of such rights is our nature as human beings. But while the existence of any right gives the possessor a claim, it also imposes a corresponding duty. The exercise of the right entails that one must do so in a responsible way - as befits a rational human being. Therefore, one must be accountable in one's pursuit of the truth or information or in one's exercise of freedom of speech. Accountability also entails that one acknowledges not just the existence of others but also, and more significantly, their dignity. It means that they have rights too that must be honoured in one's own exercise of one's rights. It is regrettable that many seem to ignore or simply violate that fundamental datum. It is, therefore, essential that the criterion of accountability features in any discussion-or exercise-of the fundamental rights which we have been discussing.

These three criteria proposed here are meant to be guidelines that hopefully can facilitate both an appreciative as well as a critical look at the issues. The earlier analysis of these shows the complexity of the situation. Ultimately, much depends on the moral sense of individuals. ${ }^{31}$ The guidelines are not intended to replace concrete measures such as laws or policies. Given the frailties of human nature and the lessons from history, society would also benefit from having the external support provided by laws and policies.

inform users of the consequences of their action for themselves and for viewers - and to awaken their sense of responsibility - before they do so. A particularly informative documentary, based on real-life experiences, was aired by Channel Four on 8 January 2013, narrated by Yasmin Bannerman and titled: "Don't Blame Facebook"

${ }^{31}$ See 'The Continuing Challenge of Ethics' in my Ethical Contexts and Theoretical Issues, pp. 219-226, where I discuss the need for developing moral sense 